\title{
A systematic review of co-responder models of police mental health 'street' triage
}

Stephen Puntis ${ }^{1 *} \mathbb{D}$, Devon Perfect ${ }^{2}$, Abirami Kirubarajan ${ }^{3}$, Sorcha Bolton ${ }^{1}$, Fay Davies ${ }^{2}$, Aimee Hayes ${ }^{4}$, Eli Harriss ${ }^{5}$ and Andrew Molodynski ${ }^{1,2}$

\begin{abstract}
Background: Police mental health street triage is an increasingly common intervention when dealing with police incidents in which there is a suspected mental health component. We conducted a systematic review of street triage interventions with three aims. First, to identify papers reporting on models of co-response police mental health street triage. Second, to identify the characteristics of service users who come in to contact with these triage services. Third, to evaluate the effectiveness of co-response triage services.

Methods: We conducted a systematic review. We searched the following databases: Ovid MEDLINE, Embase, PsycINFO, EBSCO CINAHL, Scopus, Thompson Reuters Web of Science Core Collection, The Cochrane Library, ProQuest National Criminal Justice Reference Service Abstracts, ProQuest Dissertations \& Theses, EThoS, and OpenGrey. We searched reference and citation lists. We also searched for other grey literature through Google, screening the first 100 PDFs of each of our search terms. We performed a narrative synthesis of our results.

Results: Our search identified 11,553 studies. After screening, 26 were eligible. Over two-thirds (69\%) had been published within the last 3 years. We did not identify any randomised control trials. Results indicated that street triage might reduce the number of people taken to a place of safety under S136 of the Mental Health Act where that power exists, or reduce the use of police custody in other jurisdictions.

Conclusions: There remains a lack of evidence to evaluate the effectiveness of street triage and the characteristics, experience, and outcomes of service users. There is also wide variation in the implementation of the co-response model, with differences in hours of operation, staffing, and incident response.
\end{abstract}

Keywords: Police and mental health, Street triage, Mental health crisis, Crisis team

\section{Background}

Police officers routinely encounter people who are experiencing mental health crises. In the United Kingdom (UK), estimates of the proportion of police incidents linked to mental health crises range from as little as $2 \%$ to nearly $50 \%[1,2]$. This has been increasing over recent years both in the UK and internationally [2-6], yet police often feel that they lack the skills to appropriately support those in crisis $[6,7]$.

\footnotetext{
* Correspondence: Stephen.puntis@psych.ox.ac.uk

${ }^{1}$ Department of Psychiatry, University of Oxford, Warneford Hospital, Oxford OX3 7JX, UK

Full list of author information is available at the end of the article
}

One approach to supporting police when they attend to people with mental health problems is through on-scene mental health triage. The general aim of these triage models is to introduce mental health expertise during the encounter in order to reduce the likelihood of the person in crisis being detained in police custody, and to reduce the distress caused to persons during these incidents [8]. An important parallel aim is to improve access to mental health treatment afterwards [9]. There are two main overarching models of triage: Police officers who have special mental health training (often referred to as Crisis Intervention Teams - CIT), or a co-response model where mental health professionals assist the police during incidents either in person or remotely from a control room.

(c) The Author(s). 2018 Open Access This article is distributed under the terms of the Creative Commons Attribution 4.0 International License (http://creativecommons.org/licenses/by/4.0/), which permits unrestricted use, distribution, and reproduction in any medium, provided you give appropriate credit to the original author(s) and the source, provide a link to the Creative Commons license, and indicate if changes were made. The Creative Commons Public Domain Dedication waiver (http://creativecommons.org/publicdomain/zero/1.0/) applies to the data made available in this article, unless otherwise stated. 
The co-response model is the predominant model of police mental health triage in the UK. Despite its popularity with police and healthcare workers, it has been implemented without any meaningful investigation into its effectiveness. A previous review of policing mental health interventions identified only five published studies of street triage [10]. Their review, however, included only experimental or pre-post study designs and studies of effectiveness, excluding qualitative literature, epidemiological descriptions of the population, cost-effectiveness studies, and grey literature. Given the recent emergence of the street triage intervention, these other sources are likely to be informative. It also contrasted co-response models with other mental health police interventions, and did not describe the differences between co-response models. In this article, we systematically reviewed co-response models of police mental health street triage with three aims:

1. To identify and describe different co-response models of police mental health street triage.

2. To identify demographic and clinical characteristics of service users.

3. To evaluate the evidence for the effectiveness of co-response police mental health triage.

\section{Methods}

\section{Criteria for selecting studies}

All studies had to meet three criteria detailed in Table 1.

\section{Search strategy, study screening and selection}

On the 30th April 2018, we carried out searches on the following databases: Ovid MEDLINE, Embase, PsycINFO, EBSCO CINAHL, Scopus, Thompson Reuters Web of Science Core Collection, The Cochrane Library, and ProQuest National Criminal Justice Reference Service Abstracts. We also searched grey literature via ProQuest Dissertations \& Theses, EThoS, and OpenGrey. Finally, to obtain other grey literature we entered our search terms in to Google, limiting our search to the first 100 PDF results for each search term. A search strategy was developed for MEDLINE (see Additional file 1) and adapted for the other databases. The following free text terms and phrases were used to search the title and abstract fields to retrieve relevant literature: street triag*, policing or police and triag", "mental health" and triag*, "liaison and diversion", "speciali\#ed mental health response ${ }^{*}$ ", "co-responder", coresponder*, "crisis intervention team", policing or police and "crisis team*", "mental health" and "crisis team*", policing or police and "mental health", policing or police and liaison, "section 136", or "psychiatric emergency response team".

As there is no consistent terminology for police mental health triage, these search strategies did not include $\mathrm{MeSH}$ terms. We mitigated this limitation by performing a second round of searches with a basic MeSH query to combine these sets of terms: (exp Mental Disorders/ or Triage/) and exp. POLICE/; Triage/ and exp. Mental Disorders/; Emergency Services, Psychiatric/ and exp. POLICE/. We inspected reference lists and forward citations of all included studies for further relevant literature.

Two teams of reviewers independently screened titles and abstracts (DP, AK, FD, AH). Any disagreements on eligibility were resolved through discussion with a third reviewer (SP). Following the title and abstract review, two reviewers conducted a full text review of eligible articles (DP, AK). We did not quality assess articles due to the broad range of methodologies included.

\section{Data analysis}

We conducted pilot searches in preparation for this systematic review, and during these it became clear that there were likely to be few, if any, randomised controlled trials of street triage. Therefore, we decided to conduct a narrative synthesis of our results. We extracted data from eligible studies using a standardised data extraction form. We contacted authors to request necessary information on triage model design or results data if it was missing from the article. This included data on: authors and publication type, study design, sample size and demographics, type of intervention, days and hours of operation, details of how the service was operated and staff roles, and details of outcomes recorded. We then grouped studies with similar measures and outcomes together in themes. We divided eligible articles into research studies and non-academic reports and report on them separately.

Table 1 Systematic review inclusion and exclusion criteria

\begin{tabular}{|c|c|c|}
\hline \multirow[t]{2}{*}{ Criteria } & \multicolumn{2}{|l|}{ Sub criteria } \\
\hline & Inclusion & Exclusion \\
\hline 1. A co-response model of police mental health triage & $\begin{array}{l}\text { - Include both police officers and mental health } \\
\text { workers in the response. } \\
\text { - Be a response to a police incident. }\end{array}$ & \\
\hline $\begin{array}{l}\text { 2. Describe a triage model or model development OR } \\
\text { implementation of a triage model OR epidemiological } \\
\text { study OR evaluation of effectiveness. }\end{array}$ & $\begin{array}{l}\text { - Any original published article } \\
\text { - Grey literature, service evaluations }\end{array}$ & $\begin{array}{l}\text { - Review articles, book chapters, } \\
\text { editorials or comments }\end{array}$ \\
\hline 3. English language article & & \\
\hline
\end{tabular}




\section{Results}

Our search produced 11,553 results. After removing duplicates, we screened the titles and abstracts of 6017 articles for relevance and considered 125 eligible for full text review (Fig. 1) (see Additional file 2). Twenty-four articles met full-text eligibility criteria, and we identified two further articles from searching the citations and reference lists of the eligible articles resulting in 26 articles of 23 studies included overall (Table 2) [11-36]. Our internet search for other grey literature produced 1400 results. Initial screening for relevance reduced this to 104 results, and a full-text review reduced this to 11 results.

All included articles had been conducted in Australia, Canada, the United States of America (USA) or the United Kingdom, and more than two-thirds ( $n=18$, 69\%) had been published from 2015 onwards. We did not identify any randomised controlled trials. Six articles used mixed-methods, six had qualitative methodology, four surveys, three before-and-after studies, two retrospective case-note reviews, one cross-sectional semi-structured interview, one process evaluation, one implementation study, one feasibility study, and one health economics paper. Six articles (23\%) measured data at more than one time point, with follow-up durations between 3 and 24 months.

\section{Service models}

There were 19 different triage models described in the 26 articles (Table 2). Twelve used a ride-along model, where police officer and mental health worker attend the incident in the same vehicle. Five were services with both ride-along and control room support, in which the mental health worker assists the officers remotely via telephone or police radio. Four of these described a service which used the control room as their main method of response, only using a mobile unit for particularly

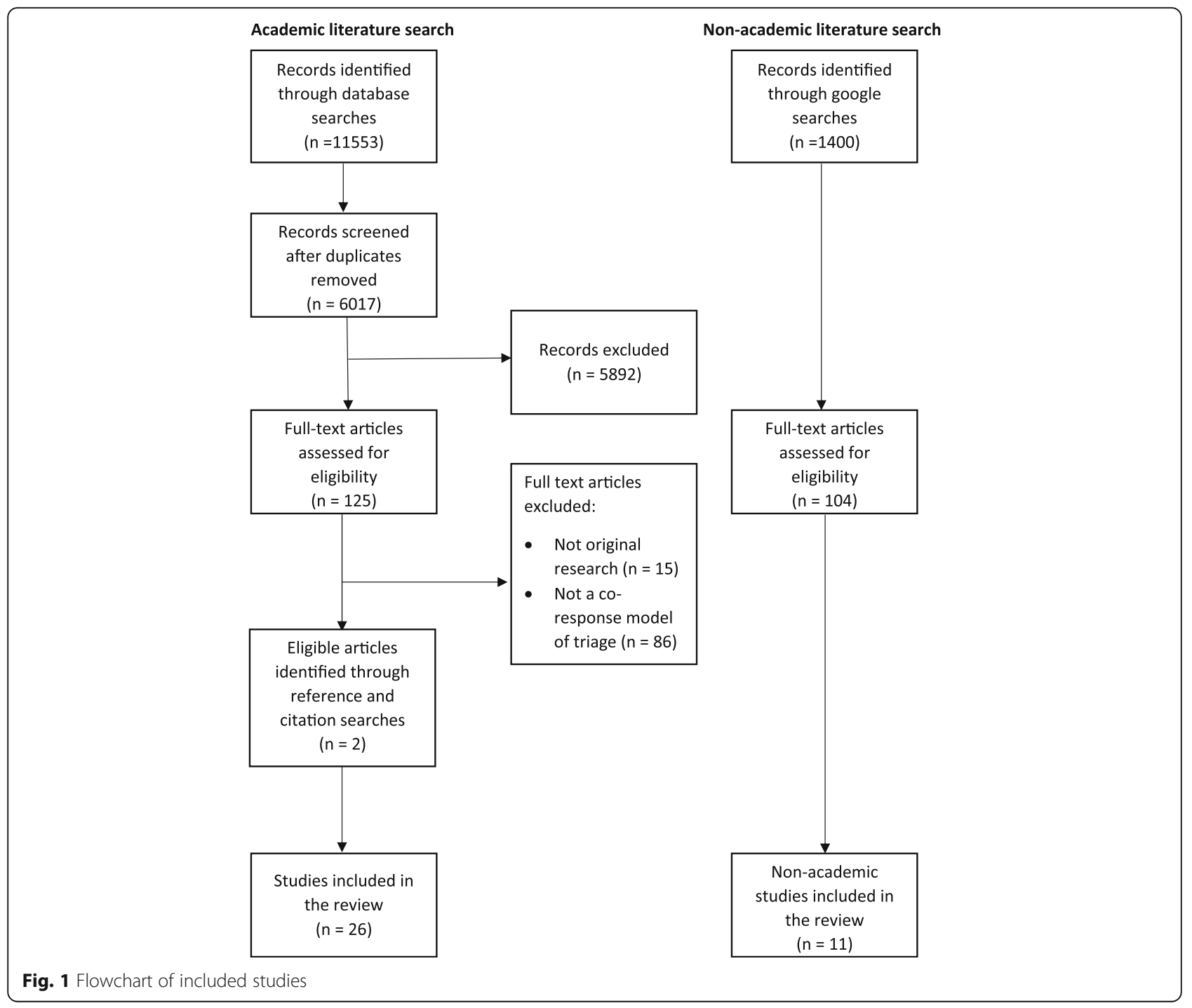




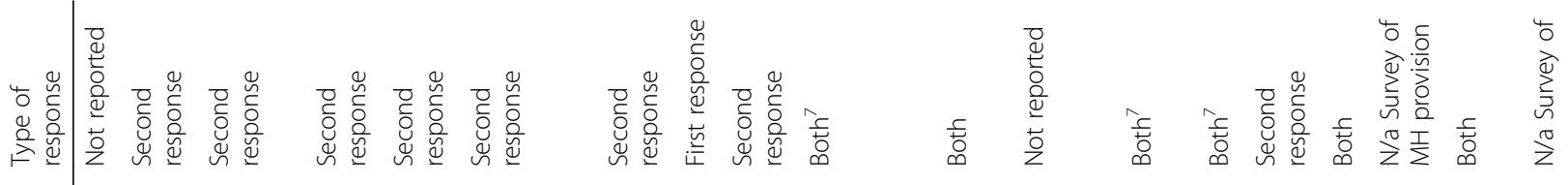

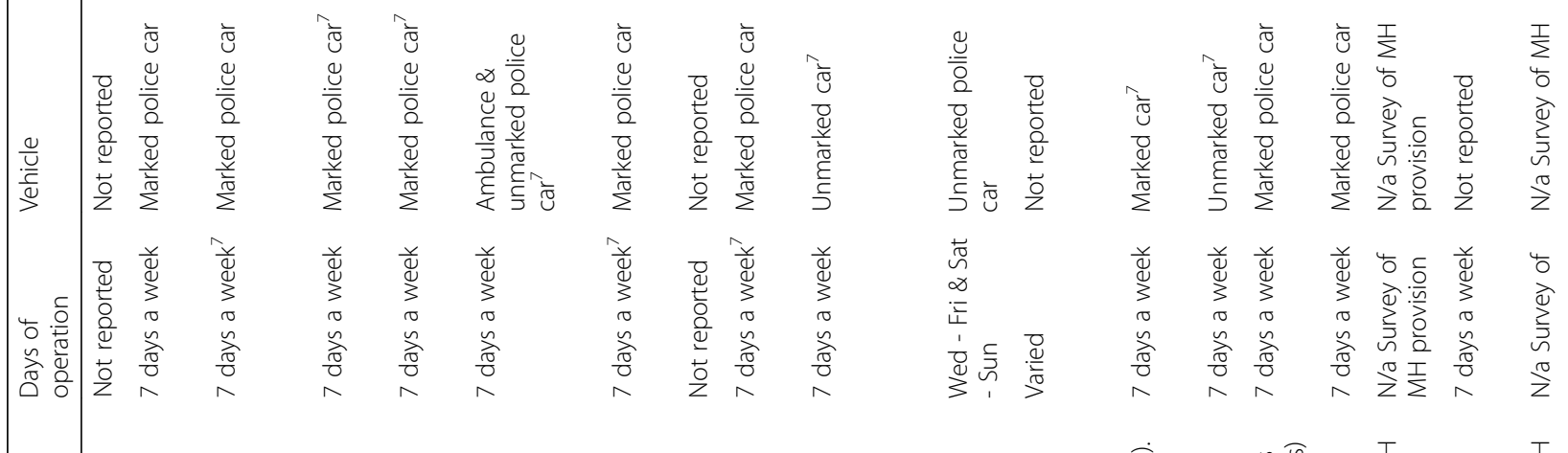

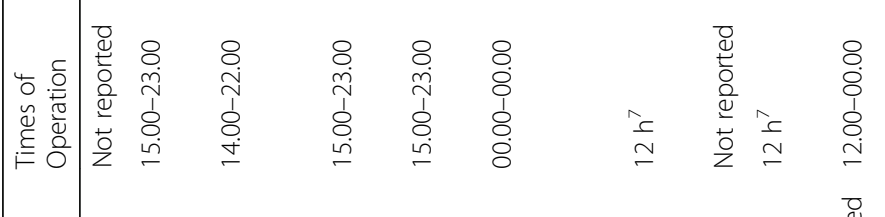

$\begin{array}{rl}\infty & \\ 0 & 0 \\ 8 & 8 \\ 0 & 0 \\ 1 & 1 \\ 0 & 0\end{array}$

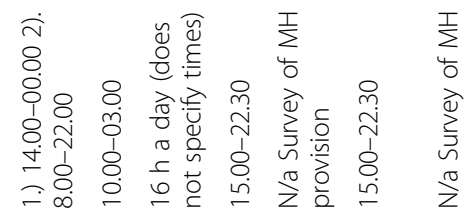

在 $Q$

ఫ্ৰ

용

,

. 


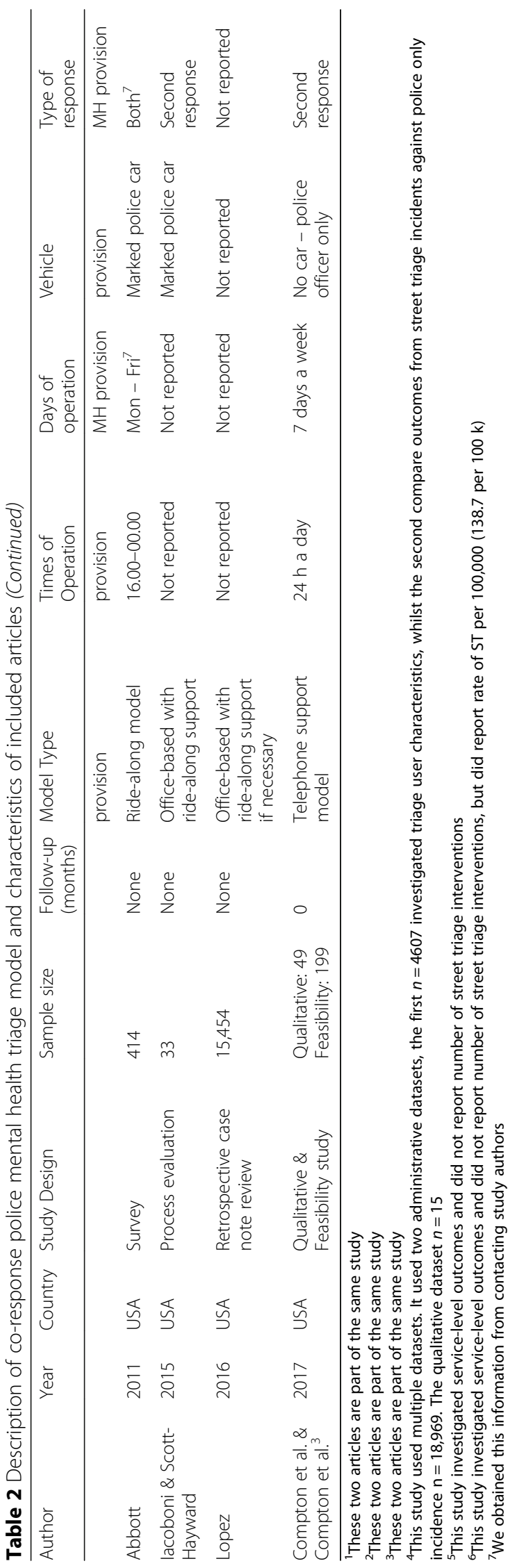


severe incidents. Two services used telephone triage as the method of response. We were unable to determine the method of one study due to a lack of adequate description, and two studies were national surveys which did not request details of the triage model.

We were able to identify how incidents were reported to the triage team for 15 models. Two took calls from emergency control rooms (e.g. 911, or a police control room), four took calls directly from police officers in the field, eight took calls from both emergency lines and police officers, and one had a direct line that emergency services, members of the public, and relevant agencies could call. Of the 15 models that reported details of the vehicles used in triage calls, nine used marked police cars, three an unmarked car, and one used an ambulance alongside an unmarked car (two models were telephone only models). Nine models described a system whereby the mobile unit was dispatched only when a normal police unit had already responded and determined the incident was safe, while one described the mobile unit acting as a first response to an incident and six used a combination of both methods of response. Data on type of response was missing from three models and the two remaining articles were the national surveys which did not collect data on the model of triage.

Twelve models had triage services that were operated 7 days a week, but only the telephone support models were run $24 \mathrm{~h}$ a day. Three models had less than 7 days a week services. Times of operation varied greatly (see Table 2), but most services were contracted to cover evening and night-time hours only.

\section{Service user characteristics Demographics}

Eight studies reported service users' age [21, 23, 27, 29, $31,32,34,35]$. Four of the eight reported mean age; 39 [27], 37.3 [31], 35.7 [29], and 40.0 [32] years respectively. One study reported mean age in pre and post intervention cohorts between 34.7 and 37.7 years [23], one reported that $46 \%$ were between ages 18 and 39 [21], whilst two categorised age into ranges, where the highest percentage lay between the 35-44 (28\%) and 35-54 (34.9\%) age categories respectively [34, 35]. More males than females were referred to the triage services, with percentages between 47 and $77 \%$ reported in eight studies $[21,23,27,29,31,32,34,35]$. Four studies, all from the USA, measured ethnicity [27, 29, 31, 32]. In two studies the most frequent reported service user ethnictiy was African-American, 65\% [31], and 61.3\% [32], with both studies taking place in the US state of Georgia, whilst in two studies, both undertaken in California, White ethnicity was the most frequent at $44.5 \%$ [27], and $33.8 \%$ [29].

\section{Previous mental health service use}

Three studies reported on the proportion of service users who had previously been in contact with mental health services. Over half of all referrals (51\%) to the Cleveland Police Street Triage service were known to the local mental health team whilst $19 \%$ were currently on the caseload of a mental health service [14]. Similarly, $48 \%$ of those who received an intervention from the Police Ambulance Crisis Response (PACER) team in Melbourne [21], and $78 \%$ of service users seen by a Los Angeles triage team had a history of psychiatric hospitalisation [27]. Between 44 and $65 \%$ of people in Jenkins and colleagues' study had had contact with a community mental health team within the past 2 weeks [23]. Diagnosis was recorded in three studies [32, 34, 35], with psychotic illnesses the most common reported diagnosis (between 26.0-42.9\%) followed by mood disorders (between 9 and 32.5\%).

\section{Co-response team involvement Reason for triage response}

The reason for triage response was only reported in three studies. The most common reason in two studies, responsible for $49 \%$ of all call-outs in Kisely and colleagues study [26], and 55\% in Lee and colleagues' [28], was concern for an individual's welfare due to suicidal behaviour. In Lamb and colleagues' study, the most common reason was "bizarre or disorganised behaviour" in $71 \%$ of call-outs [27].

\section{Repeat use of triage}

Four studies reported on repeat referrals to the service. Dyer and colleagues found that $12 \%$ of triage service users had a subsequent referral over an 18 month period [14], Huppert and colleagues found a rate of $13 \%$ over 3 months [21], Kisely and colleagues found a $20 \%$ rate over 36 months [26], whilst Lamana and colleagues found a $29.9 \%$ repeat referral rate over 12 months [35].

\section{Effectiveness of co-response police mental health triage} Many of the included studies did not look at effectiveness or outcome. Those that did took a varied approach and we report on a variety of aspects of effectiveness as a result.

\section{Reduction in police detentions}

Five studies measured changes in detention rates after the introduction of a co-response model. Four of these five studies compared the number of Section $136 \mathrm{~s}$ (S136, a police power in England and Wales which allow a police officer to detain someone whom they suspect to be mentally ill) either before and after the introduction of a co-response triage team $[18,23,24]$ or in comparison to when the co-response team was not on duty [14]. All found that the co-response model decreased the number of service users made subject to S136. Jenkins and colleagues compared mental health workers paired 
with frontline police versus mental health support from a control room and found that the face-to-face model had a significant reduction in S136 after it was introduced whilst the control room model did not [23].

Two studies compared detention in custody during co-response operational times versus operational times without co-response [19, 29]. Heslin and colleagues found a significant reduction in mental health detentions in custody whilst Lopez found that of contacts coded in the police records as 'mental health-related' $1.4 \%$ of co-response contacts resulted in arrest whilst $13.3 \%$ of police-only contacts result in arrest.

\section{Reduction in psychiatric hospitalisation}

The introduction of a co-response team resulted in a reduction in the proportion of police incidents resulting in psychiatric hospitalisation in three studies [14, 18, 31], whilst one study found an overall reduction in hospitalisation due to fewer police detentions [24]. Three studies found an increase of psychiatric hospitalisation following the introduction of street triage [16, 23, 29]. One study compared a co-responding team to a usual response and found that whilst the co-response model was more likely to lead to escort to an emergency department, these were less likely to be involuntary escorts [35], whilst another study found that once participants were involuntarily hospitaised, participants reported better percieved procedural justice but no difference in percieved coercion from the admission event [34].

\section{Perceptions of service users}

Eight studies reported on the views of those who had experienced a co-response intervention $[12,14,15,25$, $26,30,33,35]$. In five studies, participants reported that previous interactions with the police were traumatic $[12$, $14,15,30,35]$ and in four how their illness had been treated as a criminal matter rather than a mental health one [12, 15, 30, 35]. In comparison, co-response models were better at de-escalation, less threatening, and less stigmatising [12, 14, 15, 25, 26, 30,35]. Service users in one study suggested that the use of unmarked police cars and non-uniformed officers would further reduce distress and embarrassment [15].

Co-response services were reported as being more responsive to crises, with mental health workers on the scene immediately rather than a wait for police transport to a treatment destination or waiting for mental health personnel from a crisis team [12, 14, 33].

Three studies reported criticisms related to the lack of follow-up and case management. Service users often felt that there were not effective pathways to further treatment following the intervention $[14,15,25]$.

\section{Perceptions of providers}

Nine studies reported on the service providers' views of the co-responder models: three surveys, two qualitative studies, and four mixed-method designs $[11,13,14,16$, $17,25,26,28,30]$. Service providers found the service helpful and valued the service $[11,25,26,28]$, and reported improved coordination and collaboration between police, mental health services, and emergency departments [25, 28, 30]. They also reported improved speed and clarity of pathways to treatment for those seen by the triage teams $[14,16,26,28,30]$. The main criticism was the availability of the units, due to either limited operational hours or limited capacity $[26,28]$.

Three surveys reporting on police officers' perception of different triage models found no difference between perceptions of police staff on effectiveness of the service, ability to respond to those in crisis, stigma, or level of mental health training $[11,13,17]$.

\section{Cost effectiveness}

Three studies reported on the cost-effectiveness of street triage $[18,19,31]$. The average cost per crisis response was calculated to be $23 \%$ lower with the introduction of the triage programme in one analysis [31]. This was due to a reduction in hospitalisation. Heslin and colleagues found reduced overall costs due to reduced police costs, but with a smaller increase in health provider costs [19]. In a separate study by Heslin and colleagues, overall costs increased, but by less than $1 \%$ [18].

\section{Non-academic reports}

Nine of the eligible documents were evaluations of a local street triage service [37-45], one was a report on a service for strategic review [41], and one was a report on a pilot scheme of nine services [42]. Eight were from the UK, two from the USA, and one from Australia. Reports differed in both methodology and methodological quality. Eight articles measured changes to S136 before and after the introduction of a service (seven local and one wider evaluation) [37-42, 46, 47]. Five local evaluations reported a decrease in the use of S136 [37, 38, 40, 41, 46] and two an increase $[39,42]$. The report of nine evaluations found seven services with a decrease in S136 and two with an increase in S136 [47]. Five documents investigated detentions in police custody, with four finding a reduction in the use of custody [38, 39, 41, 42], and one finding no difference (although the use of custody was negligible both before and after introduction of the service) [38].

Nine documents reported on qualitative findings (eight local street triage services and the evaluation of nine sites described above) [37, 39-44, 47]. Four interviewed police, three interviewed mental health staff, two interviewed service users, and one interviewed carers. In the report of the nine pilot sites, each site conducted different interviews 
with different methodologies and different samples. Results were similar to those of the academic studies. Service users found the triage service less distressing than standard police responses [37, 39]. Police officers valued the service and found it reduced the time spent at incidents [37, 38, 42, 43, 47]. Areas identified for improvement included longer operational times [37, 43, 47], and more resources [43, 47].

\section{Discussion}

The number of publications reporting on co-response models of police mental health triage has surged, with more than two-thirds of the studies included in this review published in the last 3 years. The co-response model of triage is now an established intervention in the US, Australia, and Canada, and has become the dominant model of mental health crisis response used by the police in the UK.

Overall, we found that co-response models were associated with a reduction in the use of police powers of detention (such as the use of S136) a reduction in detainment in police custody. Unfortunately, due to the design of the studies one cannot determine whether this is due to the intervention or other factors such as changes in policy, changes in mental health provision, or greater public scrutiny of mental health detentions [48]. Evidence from the qualitative studies we included in this review suggests that service users found the co-response interventions less distressing and less criminalising than a standard police response. Service users also reported quicker access to mental health support at the time of crisis, although this did not extend to gaining access to mental health services at follow-up.

In conducting this review, we identified three major limitations of the current evidence for co-response triage, a) the lack of information on the characteristics of service users b) the lack of detail when describing co-response models and the variation in their operationalisation and, c) the lack of rigorous comparative research on effectiveness.

\section{The lack of information on characteristics of service users}

Few studies measured the demographic and clinical characteristics of triage service users or their reason for referral. From the data reported, those who are middle-aged and male are slightly overrepresented, as are those with psychotic illnesses and previous mental health history. The data we identified in both the academic and non-academic literature suggest that the majority of service users are already know to mental health teams, and between 10 and $20 \%$ have multiple referrals to the triage team.

Whilst psychiatric inpatient beds have declined over the last 60 years, the provision of forensic beds and the proportion of the mentally ill in prison has increased in both the US and Europe [5, 49]. Deinstitutionalisation without appropriate community treatment may have led to increased criminalisation of the mentally ill [50]. Police triage services are designed to divert those with mental illness away from police custody, but providing appropriate support prior to a crisis point may reduce the need for an intervention by emergency services [51]. There remains, however, a group of service users who come into contact with triage who have no previous mental health service use or known psychopathology. Measuring who is referred, their history leading up to referral, and the nature of the referral may improve our understanding of this vulnerable population. This may in turn allow us to be clear about the circumstances in which the use of the police-triage resource is appropriate and those in which it can be avoided. This could have significant implications for service use and most importantly for patient experience and outcome.

\section{Variations in the co-response model}

Many of the papers included in this review did not adequately describe their model of triage. Less than half reported operational hours and only two-thirds described their method of response to incidents. When contacting the authors, many of these details were available, which suggests issues of how triage is reported in the literature rather than poor model specification.

There was marked variation in how co-response models were operationalised. There were differences in times and days of operation, whether the unit was a first or second-response option, whether the police officer and mental health worker were co-located, whether a mobile unit was dispatched or not, and the mode of transportation to the incident (marked or unmarked vehicles). There was also limited, if any, information on other mental health provision in the study area.

Local context will always inform model implementation, and rightly so. There must, however, be efforts to understand which components of the model are most effective and most acceptable to service users, and equally which are not. Where good practice is identified, such as the use of unmarked cars and non-uniformed police officers, these can be rigorously tested.

The current heterogeneity in model implementation creates a problem of circularity, whereby service providers cannot follow good practice guidelines because there are none. At the same time, commissioners cannot establish good practice because each model is idiosyncratic and cannot easily be compared.

This may in part be due to the lack of precise reporting of co-response models. Reporting aspects such as the location and composition of members of the team, hours of operation, referral processes, all potential response methods, and mode of transportation should all be reported as a minimum dataset. In Table 3, we suggest a framework for 
Table 3 A suggested framework for collecting and reporting co-response triage models

\begin{tabular}{ll}
\hline Topic & Variable to report \\
\hline Identify as co-response & Name of service \\
triage service & $\begin{array}{l}\text { Identify as co-response } \\
\text { model of triage }\end{array}$ \\
Model characteristics & Model of co-response
\end{tabular}

Method of referral to co-response team

Team staffing and roles

Days and hours of operation

Team Location

Vehicle involved in triage response (if any)

Local context
Timing of response

Description of variable and reason for reporting

Give the name of the service to enable grouping of models and their comparison.

Include a sentence in the service description to signpost to readers and researchers that the service is a co-response model of police mental health triage.

Define the model of how the mental health professional assists the police officer during the incident. Ride-along models are those in which the police officer (PO) and mental health $(\mathrm{MH})$ worker attend the incident together in a vehicle. Ride-separate models are when $\mathrm{PO}$ and $\mathrm{MH}$ worker arrive at the incident separately. Telephone Support models are those in which the $\mathrm{MH}$ worker provides assistance via a telephone or radio. Services that provide a combination of these models should specify when each model is used.

Describe how crisis incidents are referred to the triage team (e.g. emergency response, direct from police officers, publicly available direct phone line), and from whom triage can take referrals (e.g. police officers, other emergency services, mental health services, the public, etc.)

Describe whether the co-response team acts as a first responder, where the team can be referred to and attend incidents prior to any other police involvement, or second responder, where the team is referred following an initial police response.

Outline the team composition and responsibilities

Describe the working hours of members of the co-response team. Be explicit if hours differ for different types of response, or members of response.

Describe where each member of the team is located during a usual triage shift.

If applicable, describe how the co-response team attend the triage incident (e.g. in a marked police car, unmarked car, ambulance, etc.)

Describe the geographic elements (e.g. rural versus city, large area vs small area) and local population to improve readers' understanding of the local context in to which the triage service is placed.

Local mental health provision Describe local mental health provision and agencies working closely with the triage team and linked partner agencies (if any) to improve understanding of where triage fits within crisis services and wider mental health provision reporting triage models in future studies to enable model comparison.

\section{The lack of controlled research on the effectiveness of co-response models of police mental health triage}

There is a striking lack of evidence for the effectiveness of co-response models of triage despite the substantial investment these services have received. We did not identify any randomised control trials. We identified one controlled before-and-after study, which found better engagement with mental health services following the intervention, but did not measure other important clinical follow-up data such as hospitalisation [26].

There would be significant challenges conducting a randomised trial of street triage, such as lack of blinding, consenting participants, and maintaining model fidelity. Whilst these difficulties are not insurmountable, other designs (such as longitudinal data with propensity score matching) may be more feasible. For instance, a quasi-experimental design such as propensity score matching could avoid the difficulty of gaining consent prior to randomisation by retrospectively matching those who have received a triage intervention with a sample who have not. This would incur less cost than an appropriate cluster randomised controlled trial, but would remain only an approximation of randomisation and would require careful covariate selection.

This lack of evidence needs to be urgently addressed as we currently have little understanding of both the immediate and the long-term clinical and functional outcomes following a triage intervention, nor any identification of potential adverse events resulting from it.

\section{Strengths and limitation}

This is the first systematic review dedicated solely to investigating co-response street triage. We used a search strategy which included broad criteria and included many different databases and grey literature searches to ensure we captured all studies of street triage. We excluded reviews, book chapters, editorials, and non-English language articles which may have resulted in us missing some relevant literature.

We were unable to assess risk of bias due to the broad range of methodologies used in our included studies, and we decided to include this heterogeneous mix of studies rather than focus on any single methodology due to the sparse literature.

\section{Conclusion}

Preliminary evidence suggests that co-response models of mental health police triage may reduce the use of 
police powers of detention on people with mental illness and be more acceptable to service users than a standard response. However, there remains a lack of quality of reporting in studies, few controlled studies investigating the effectiveness of co-response triage, and a lack of focus on the characteristics and outcomes of service users.

There are many unanswered questions about the effectiveness of police mental health triage. Is a police response the most appropriate response for people in mental health crisis? Alternatively, would an ambulance-based mental health crisis response be more effective, and more acceptable, than a police one? Is the perceived increased need for police mental health intervention due to a lack of appropriate mental health support elsewhere in the healthcare system? How can we better care for those who repeatedly make use of the triage service, for their benefit and for other users who need access?

Given the considerable recent investment of resources by police and mental health services, thoughtful evaluation of triage services should lead development of models rather than be left as an afterthought. Rigorous data on outcomes, both immediate and long-term, following a triage intervention is needed. We also need further exploration of service users and their carers' experience of triage, and their participation in the design of these services. Finally, we need to move towards better model description and evaluation, with the aim of creating fidelity indicators linked to good practice and good outcomes.

\section{Additional files}

Additional file 1: Search strategy. Systematic review search strategy in detail. (DOCX $21 \mathrm{~kb})$

Additional file 2: Papers excluded at full text review. Reference list of all the papers excluded during the full-text review stage. (DOCX $30 \mathrm{~kb}$ )

\section{Abbreviations}

CIT: Crisis Intervention Team; MH: Mental health; PACER: Police Ambulance Crisis Response; PDF: Portable Document Format; PO: Police officer; UK: United Kingdom

\section{Funding}

This research was funded by the National Institute for Health Research (NIHR) Collaboration for Leadership in Applied Health Research and Care Oxford at Oxford Health NHS Foundation Trust. The views expressed are those of the author(s) and not necessarily those of the NHS, the NIHR or the Department of Health.

\section{Availability of data and materials}

Search terms are included in the Additional file 1. All data will be made available by the corresponding author on request.

\section{Authors' contributions}

$\mathrm{SP}, \mathrm{AM}, \mathrm{AH}$, and FD planned the study. SP and $\mathrm{EH}$ developed the search strategy. DP, AK, AH, FD, and SB conducted the searches. SP, DP, AK, AM, and SB conducted the analysis. SP wrote the initial manuscript and SP and SB wrote the revisions. All authors contributed to revisions and approved the final manuscript.
Ethics approval and consent to participate

Not applicable.

\section{Consent for publication}

Not applicable.

\section{Competing interests}

The authors declare that they have no competing interests.

\section{Publisher's Note}

Springer Nature remains neutral with regard to jurisdictional claims in published maps and institutional affiliations.

\section{Author details}

${ }^{1}$ Department of Psychiatry, University of Oxford, Warneford Hospital, Oxford OX3 7JX, UK. ²Oxford Health NHS Foundation Trust, Warneford Hospital, Oxford OX3 7JX, UK. ${ }^{3}$ MD Program, University of Toronto Faculty of Medicine, Toronto, ON M5S 1A8, Canada. ${ }^{4}$ Coventry and Warwickshire Partnership NHS Trust, Wayside House, Wilsons Lane Coventry, Warwickshire CV6 6NY, UK. ${ }^{5}$ Bodleian Health Care Libraries, University of Oxford, Oxford, UK.

Received: 7 February 2018 Accepted: 6 August 2018

Published online: 15 August 2018

References

1. House of Commons Home Affairs Committee. Policing and mental health eleventh report of session 2014-2015. London: The Stationary Office Limited; 2015.

2. College of Policing. College of policing analysis: estimating demand on the police service. London; College of Policing; 2015.

3. Clifford K. The thin blue line of mental health in Australia. Police Pract Res Int J. 2010;11(4):355-70.

4. Coleman $\mathrm{TG}$, Cotton $\mathrm{DH}$. Reducing risk and improving outcomes of police interactions with people with mental illness. J Police Crisis Negotiations. 2010;10(1-2):39-57.

5. Lamb HR, Weinberger LE, DeCuir WJ Jr. The police and mental health. Psychiatr Serv. 2002;53(10):1266-71.

6. Wells W, Schafer JA. Officer perceptions of police responses to persons with a mental illness. Policing. 2006;29(4):578-601.

7. Cooper VG, Mclearen AM, Zapf PA. Dispositional decisions with the mentally ill: police perceptions and characteristics. Police Q. 2004;7(3):295-310.

8. Riley $\mathrm{G}$, et al. 'A frightening experience': detainees' and carers' experiences of being detained under section 136 of the mental health act. Med Sci Law. 2011;51(3):164-9.

9. Hampson M. Raising standards in relation to section 136 of the mental health act 1983. Adv Psychiatr Treat. 2011;17(5):365-71.

10. Kane E, Evans E, Shokraneh F. Effectiveness of current policing-related mental health interventions: a systematic review. Crim Behav Ment Health. 2017; https://doi.org/10.1002/cbm.2058.

11. Abbott SE (2011) Evaluating the impact of a Jail Diversion Program on police officer's attitudes toward the mentally ill.

12. Boscarato $\mathrm{K}$, et al. Consumer experience of formal crisis-response services and preferred methods of crisis intervention. Int J Ment Health Nurs. 2014; 23(4):287-95.

13. Deane MW, et al. Emerging partnerships between mental health and law enforcement. Psychiatr Serv. 1999:50(1):99-101.

14. Dyer W, Steer M, Biddle P. Mental health street triage. Policing. 2015;9(4): 377-87.

15. Evangelista $E$, et al. Crisis averted: how consumers experienced a police and clinical early response (PACER) unit responding to a mental health crisis. Int J Ment Health Nurs. 2016;25(4):367-76.

16. Fahim C, Semovski V, Younger J. The Hamilton mobile crisis rapid response team: a first-responder mental health service. Psychiatr Serv. 2016:67(8):929.

17. Hails J, Borum R. Police training and specialized approaches to respond to people with mental illnesses. NCCD News. 2003:49(1):52-61.

18. Heslin $\mathrm{M}$, et al. Costs of the police service and mental healthcare pathways experienced by individuals with enduring mental health needs. $\mathrm{Br} J$ Psychiatry. 2017;210(2):157-64.

19. Heslin $\mathrm{M}$, et al. Decision analytic model exploring the cost and cost-offset implications of street triage. BMJ Open. 2016;6(2):e009670. 
20. Horspool K, Drabble SJ, Cathain AO. Implementing street triage: a qualitative study of collaboration between police and mental health services. BMC Psychiatry. 2016;16(1):313.

21. Huppert D, Griffiths M. Police mental health partnership project: police ambulance crisis emergency response (PACER) model development. Australas Psychiatry. 2015;23(5):520-3.

22. lacoboni MS. Burbank police department mental health evaluation team (MHET) evaluation. Long Beach: California State University; 2015.

23. Jenkins $\mathrm{O}$, et al. Police liaison and section 136: comparison of two different approaches. BJPsych Bull. 2017;41(2):76-82

24. Keown P, et al. Too much detention? Street Triage and detentions under section 136 Mental Health Act in the North-East of England: a descriptive study of the effects of a Street Triage intervention. BMJ Open. 2016;6(11):e011837.

25. Kirst $M$, et al. Examining implementation of mobile, police-mental health crisis intervention teams in a large urban center. J Ment Health. 2015;24(6): 369-74

26. Kisely S, et al. A controlled before-and-after evaluation of a mobile crisis partnership between mental health and police services in Nova Scotia. Can J Psychiatry. 2010;55(10):662-8.

27. Lamb HR, et al. Outcome for psychiatric emergency patients seen by an outreach police- mental health team. Psychiatr Serv. 1995;46(12):1267-71.

28. Lee SJ, et al. Outcomes achieved by and police and clinician perspectives on a joint police officer and mental health clinician mobile response unit. Int J Ment Health Nurs. 2015;24(6):538-46.

29. Lopez H. A descriptive study of LAPD's co-response model for individuals with mental illness. Long Beach: California State University; 2016.

30. McKenna $\mathrm{B}$, et al. Police and mental health clinician partnership in response to mental health crisis: a qualitative study. Int J Ment Health Nurs. 2015; 24(5):386-93.

31. Scott RL. Evaluation of a mobile crisis program: effectiveness, efficiency, and consumer satisfaction. Psychiatr Serv. 2000;51(9):1153-6.

32. Compton MT, Anderson S, Broussard B, Ellis S, Halpern B, Pauselli L, O'Neal $M$, Druss BG, Johnson M. A potential new form of jail diversion and reconnection to mental health services: II. Demonstration of feasibility. Behav Sci Law. 2017;35(5-6):492-500

33. Compton MT, Halpern B, Broussard B, Anderson S, Smith K, Ellis S, Griffin K, Pauselli L, Myers N. A potential new form of jail diversion and reconnection to mental health services: I. Stakeholders' views on acceptability. Behav Sci Law. 2017;35(5-6):480-91.

34. Furness T, Maguire T, Brown S, McKenna B. Perceptions of procedural justice and coercion during community-based mental health crisis: a comparison study among stand-alone police response and co-responding police and mental health clinician response. Policing. 2016;11(4):400-9.

35. Lamanna D, Shapiro GK, Kirst M, Matheson Fl, Nakhost A, Stergiopoulos V. Co-responding police-mental health programmes: service user experiences and outcomes in a large urban Centre. Int J Ment Health Nurs. 2018;27(2): 891-900.

36. Ligon J, Thyer BA. Client and family satisfaction with brief community mental health, substance abuse, and mobile crisis services in an urban setting. Crisis Interv. 2000;6(2):93-9.

37. Senker S and Scott M (2016) Essex Street Triage evaluation December 2015 https://bit.ly/2GZyxln

38. Clark J (2016) Policing mental health in Derbyshire. https://bit.ly/2LDrdWo.

39. Hobson Z, Grossmith L, Dawson P.(2015) Research into the London mental health street triage pilot. MOPAC evidence and insight. https://bit.ly/2GZVsDe

40. Edmondson D, and Cummins I (2014) Oldham mental health phone Triag/ RAID pilot project. https://bit.ly/2MAdboE

41. Oxford Health NHS Foundation Trust. Oxfordshire mental health street triage pilot. Oxford: Oxford Health NHS Foundation Trust; 2015.

42. Irvine AL, Allen L, Webber MP. Evaluation of the Scarborough, Whitby and Ryedale Street Triage service. research report: Department for Social Policy and Social Work, University of York; 2016. orcid.org/0000-0003-3604-1376

43. Fitts M, Robertson J (2017) Review of the Cairns mental health co-responder project. https://bit.ly/2sgYvCF

44. Frank J, Eck J, Ratansi S (2004) Mobile crisis team/police collaboration evalation. https://bit.ly/2KFyUcP.

45. Ruiz A, Long B, Schnell, R (2005) Psychiatric emergency response team and homeless outreach team: San Diego police department. https://bit.ly/ $2 \mathrm{~L} 4 \mathrm{bn} 60$

46. Larmour, M. (2015) Strategic policing and crime board.1 December 2015. Mental health. https://bit.ly/2kvMo03
47. Reveruzzi B, Pilling S. Street Triage: report on the evaluation of nine pilot schemes in England. London: University College London; 2016.

48. Cummins I, Edmondson D. Policing and street triage. J Adult Prot. 2016; 18(1):40-52.

49. Fakhoury W, Priebe $S$. The process of deinstitutionalization: an international overview. Curr Opin Psychiatry. 2002;15(2):187-92.

50. Lamb HR, Bachrach LL. Some perspectives on deinstitutionalization. Psychiatr Serv. 2001;52(8):1039-45.

51. Paton F, et al. Improving outcomes for people in mental health crisis: a rapid synthesis of the evidence for available models of care. Health Technol Assess. 2016:20(3):1-162
Ready to submit your research? Choose BMC and benefit from:

- fast, convenient online submission

- thorough peer review by experienced researchers in your field

- rapid publication on acceptance

- support for research data, including large and complex data types

- gold Open Access which fosters wider collaboration and increased citations

- maximum visibility for your research: over $100 \mathrm{M}$ website views per year

At $\mathrm{BMC}$, research is always in progress.

Learn more biomedcentral.com/submissions 